\title{
Synthesis and modification of two-dimensional crystalline silicon nanosheets
}

\author{
Hideyuki NAKANO \\ TOYOTA CENTRAL R\&D LABS., INC., 41-1 Yokomichi, Nagakute, Aichi 480-1192, Japan
}

\begin{abstract}
Soft chemical synthesis of silicon nanosheets (SiNSs) and functionalized modified SiNSs are reviewed. Free standing SiNSs with sub-nanometer thicknesses have been prepared by exfoliating layered silicon compounds, and they are found to be composed of crystalline single-atom-thick silicon layers. SiNSs are new silicon nanomaterials, as are silicon nanoparticles and nanowires. Organic modified SiNS can be prepared by modifying a layered polysilane, which has an analogous structure to that of graphite, and this allows the properties of the SiNS to be controlled in order to make it suitable for particular applications. The potential applications of these SiNSs and organic modified SiNSs are also reviewed.
\end{abstract}

(๑2014 The Ceramic Society of Japan. All rights reserved.

Key-words : Silicon, Nanosheet, Exfoliation, Soft chemistry, Modification

[Received April 28, 2014; Accepted June 23, 2014]

\section{Introduction}

Silicon nanomaterials have attracted increasing amounts of attention, not only because of the many technological applications they currently have and that are anticipated, but also in terms of research into the fundamental principles relating to them. For example, highly porous silicon produced by electrochemical dissolution exhibited visible photoluminescence at room temperature. ${ }^{1), 2)}$ Low-dimensional nanomaterials are of particular interest because they may exhibit anisotropic and/or dimensiontunable properties, both of which are important attributes in nanodevice applications. ${ }^{3)}$ Recently, zero-dimensional crystal Si nanomaterials, i.e., Si nanoparticles, ${ }^{4), 5)}$ and one-dimensional nanomaterials, i.e., Si nanowires ${ }^{6), 7)}$ and $\mathrm{Si}$ nanotubes, ${ }^{8), 9)}$ have been successfully synthesized. Although controlling the dimensions of the materials produced is difficult because the melting point of silicon is higher than $1400^{\circ} \mathrm{C}$, the fabrication techniques have been studied intensively with the aim of improving the sizes and chemical stabilities of the materials produced and achieving high yields. However, two-dimensional (2D) crystal silicon nanomaterials, i.e., Si nanosheets (SiNSs), have not been extensively developed.

In 1996, Sasaki et al. defined "nanosheets" in a detailed study on the exfoliation of layered titanium oxide. ${ }^{10)}$ Nanosheets are generally characterized as having a thickness in the order of nanometers and lateral dimensions ranging from the submicrometer to the micrometer scale. The most important feature of nanosheets is their extraordinarily high specific surface areas, which makes them promising candidates for various applications, depending on their specific physical properties. With respect to materials science, nanosheets can be used as building blocks for novel supramolecular assemblies with applications in nanoscience and nanotechnology. ${ }^{11), 12)}$ Therefore, many kinds of nanosheets have been prepared and their unique properties have been demonstrated. A process involving cation exchange has

$\uparrow$ Corresponding author: H. Nakano; E-mail: hnakano@mosk. tytlabs.co.jp been used to create inorganic nanosheets of layered compounds, clay minerals, ${ }^{13)}$ metal chalcogenides, ${ }^{14), 15)}$ phosphonates, ${ }^{16), 17)}$ and layered transition-metal oxides. ${ }^{18)-20)}$ Extensive research has also been performed on exfoliating anion-exchangeable layered double hydroxides. ${ }^{21)-23)}$ Moreover, few layered van der Waals materials, such as $\mathrm{MoS}_{2}$ and $\mathrm{NbSe}_{2}$, have been prepared using a mechanical exfoliation process and have had their properties studied since the 1960s. ${ }^{24-26)}$ In 2004, graphene was produced by the micromechanical cleavage of graphite. ${ }^{27)}$ Graphene is a twodimensional material with unique electronic properties that are qualitatively different from those of standard semiconductors such as silicon. ${ }^{28)}$ On the other hand, the fabrication of silicene by the ultrahigh vacuum deposition of silicon atoms onto a metallic substrate has recently been reported. ${ }^{29), 30)}$ Silicene is a relatively new allotrope of silicon and can be viewed as the silicon version of graphene. Therefore, silicene shares many of the fascinating properties of graphene, such as the so-called Dirac electronic dispersion. However, the structure of silicene is slightly different from that of graphene, leading to a few major differences in properties, such as its ability to open a bandgap in the presence of an electric field or on a substrate, which is a key property in digital electronic applications.

As for previously reported syntheses, the top-down approach is a reliable method of synthesizing SiNSs, if suitable 2D Si structures are available. Therefore, we have attempted to produce SiNSs from Zintl-phase $\mathrm{CaSi}_{2}$, layered polysilane $\left(\mathrm{Si}_{6} \mathrm{H}_{6}\right)$, and siloxene $\left[\mathrm{Si}_{6} \mathrm{H}_{3}(\mathrm{OH})_{3}\right]$, which are crystalline layered polymers that each have a backbone of puckered 2D Si layers that are similar to the (111) planes in 3D crystalline Si. The single silicon atom layers in these layered silicon compounds only weakly interact with each other, but they are not easily exfoliated and do not dissolve in either organic or inorganic solvents. However, our research group has succeeded in synthesizing SiNSs by exfoliating $\mathrm{Si}_{6} \mathrm{H}_{6}$ and $\mathrm{Si}_{6} \mathrm{H}_{3}(\mathrm{OH})_{3}$, with some modifications of the usual exfoliation methods. In this review, we mainly describe the recent results of our attempts to prepare SiNSs and organic modified SiNSs, and the potential applications of these SiNSs. 


\section{Layered silicon compounds used as starting materials}

The crystal structures of layered silicon compounds that have been used as starting materials for producing SiNSs are illustrated in Fig. 1. Many Zintl silicides have been produced, and $\mathrm{CaSi}_{2}$ has $2 \mathrm{D}$ puckered silicon sheets in which the $\mathrm{Si}_{6}$ rings are interconnected. The puckered $\left(\mathrm{Si}^{-}\right)_{\mathrm{n}}$ polyanion layers are separated from each other by planar monolayers of $\mathrm{Ca}^{2+}$. Treating $\mathrm{CaSi}_{2}$ with ice-cold concentrated aqueous $\mathrm{HCl}$ causes it to be topotactically transformed into a green-yellow solid, which is the layered siloxene $\left[\mathrm{Si}_{6} \mathrm{H}_{3}(\mathrm{OH})_{3}\right]$, with the release of hydrogen gas, as described in reaction $1{ }^{31)}$

$$
\begin{aligned}
& 3 \mathrm{CaSi}_{2}+6 \mathrm{HCl}+3 \mathrm{H}_{2} \mathrm{O} \\
& \quad \rightarrow \mathrm{Si}_{6} \mathrm{H}_{3}(\mathrm{OH})_{3}+3 \mathrm{CaCl}_{2}+3 \mathrm{H}_{2}
\end{aligned}
$$

The crystalline sheets have puckered 2D Si layers that are similar to crystalline $\mathrm{Si}(111)$ layers, and the $\mathrm{Si}$ atoms in the layers are stabilized by terminal hydrogen or hydroxide groups that point out of the layer plane. $\mathrm{CaSi}_{2}$ was found to change into the layered polysilane $\left(\mathrm{Si}_{6} \mathrm{H}_{6}\right)$ at temperatures below $-30^{\circ} \mathrm{C}$, without hydrogen being evolved, as shown in reaction $2 .^{32), 33)}$ This means that the additional reactions between the Si layer and water do not occur.

$$
3 \mathrm{CaSi}_{2}+6 \mathrm{HCl} \rightarrow \mathrm{Si}_{6} \mathrm{H}_{6}+3 \mathrm{CaCl}_{2}
$$

The structures of $\mathrm{Si}_{6} \mathrm{H}_{6}$ and $\mathrm{Si}_{6} \mathrm{H}_{3}(\mathrm{OH})_{3}$ are similar, but in $\mathrm{Si}_{6} \mathrm{H}_{6}$ all of the $\mathrm{Si}$ atoms are terminated with a hydrogen atom, and there are no oxygen atoms. Interlayer bonding between adjacent polymer sheets is weaker in both $\mathrm{Si}_{6} \mathrm{H}_{3}(\mathrm{OH})_{3}$ and $\mathrm{Si}_{6} \mathrm{H}_{6}$ than in $\mathrm{CaSi}_{2}$, because the bonding consists of only weak van der Waals forces in $\mathrm{Si}_{6} \mathrm{H}_{6}$ and weak van der Waals forces and hydrogen bonds in $\mathrm{Si}_{6} \mathrm{H}_{3}(\mathrm{OH})_{3}$. Recently, we synthesized several alkoxideterminated organosiloxenes $\left(\mathrm{Si}_{6} \mathrm{H}_{5} \mathrm{OR}\right.$, where $\mathrm{R}=\mathrm{Bu}, \mathrm{C}_{12} \mathrm{H}_{25}$, $\mathrm{Bn}$, or $\left.\mathrm{CH}_{2} \mathrm{COOMe}\right)^{34)}$ following a method that was reported previously. ${ }^{35)}$ Using an organic moiety that is longer or bulkier than a methoxy or ethoxy group increases the interlayer distance beyond those found for $\mathrm{Si}_{6} \mathrm{H}_{3}\left(\mathrm{OCH}_{3}\right)_{3}$ and $\mathrm{Si}_{6} \mathrm{H}_{3}\left(\mathrm{OC}_{2} \mathrm{H}_{5}\right)_{3}$.

\section{Synthesis of nanosheets}

We attempted to prepare SiNSs by chemically exfoliating $\mathrm{CaSi}_{2}$, which has interconnected $\mathrm{Si}_{6}$ rings (Fig. 1). One of the most important techniques for exfoliating $\mathrm{CaSi}_{2}$ to give its elementary layers is by adjusting the charges on the silicon

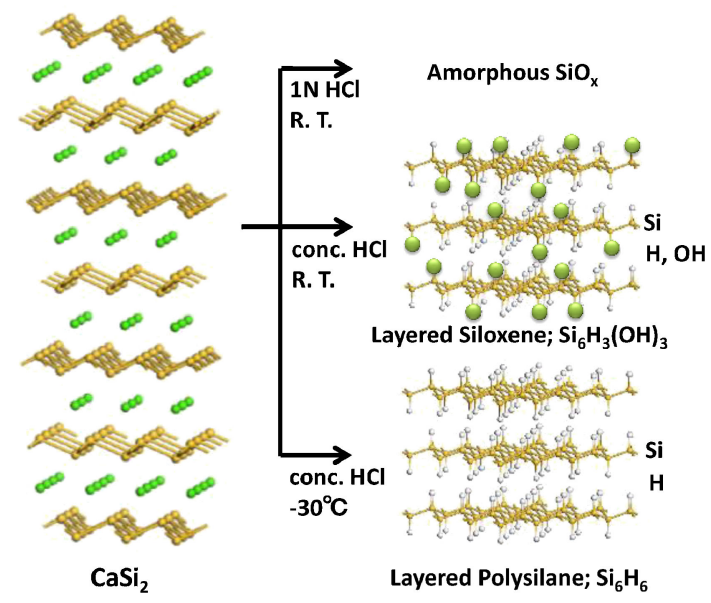

Fig. 1. Schematic illustration of layered silicon compounds. layers. The $\mathrm{CaSi}_{2}$ formula with the formal charges included is $\mathrm{Ca}^{2+}\left(\mathrm{Si}^{-}\right)_{2}$; thus, the electrostatic interactions between the $\mathrm{Ca}^{2+}$ and $\mathrm{Si}^{-}$layers are strong. It is, therefore, very important to decrease the amount of negative charge on the silicon layers to allow exfoliation to occur. To achieve this, $\mathrm{Mg}$-doped $\mathrm{CaSi}_{2}$ was used as a starting material to decrease the strength of the interactions between the $\mathrm{Ca}^{2+}$ and $\left(\mathrm{Si}^{-}\right)_{\mathrm{n}}$ layers. $\left.{ }^{36}\right)$ The immersion of bulk $\mathrm{CaSi}_{1.85} \mathrm{Mg}_{0.15}$ in a solution of propylamine hydrochloride led to the deintercalation of the calcium ions, which was accompanied by the evolution of hydrogen. The $\mathrm{CaSi}_{1.85} \mathrm{Mg}_{0.15}$ was then converted into a mixture of SiNSs and an insoluble black metallic solid. A light-brown suspension containing SiNSs was obtained after the sediment had been removed from the bottom of the flask. The composition of the SiNSs obtained was determined to be $\mathrm{Si}: \mathrm{Mg}: \mathrm{O}=7.0: 1.3: 7.5$, indicating that the SiNSs were preferentially exfoliated from sections of the silicon layers where magnesium atoms were present.

The dimensions of the nanosheets were determined by direct observations using atomic force microscopy (AFM), and the sheets were found to be $0.37 \mathrm{~nm}$ thick with lateral dimensions of 200-500 nm [Figs. 2(a) and 2(b)]. The crystallographic thickness of the SiNS was calculated, from its atomic architecture, to be $0.16 \mathrm{~nm}$, and the difference between this value and that obtained using AFM indicates that the surfaces of the SiNSs were stabilized by oxygen capping atoms. High resolution AFM images revealed that the closest distance between the atoms (dot-like marks in the AFM image) was $0.41 \pm 0.02 \mathrm{~nm}$ [Fig. 2(c)], which is slightly larger than the distance between $\mathrm{Si}$ atoms in the $\mathrm{Si}(111)$ plane in bulk crystalline silicon $(0.38 \mathrm{~nm})$. We concluded that the core of each nanosheet consisted of a single-crystal silicon monolayer with the thickness of a slightly squashed $\mathrm{Si}(111)$ plane.

Another approach that was used was to prepare $\mathrm{Si}_{6} \mathrm{H}_{3}(\mathrm{OH})_{3}$ nanosheets using a surfactant. ${ }^{37)} \mathrm{Si}_{6} \mathrm{H}_{3}(\mathrm{OH})_{3}$ was dispersed in sodium dodecylsulfate $\left(\mathrm{C}_{12} \mathrm{H}_{25} \mathrm{OSO}_{3} \mathrm{Na}\right)$, and then the mixture was stirred at room temperature for 10 days. This produced a translucent colloidal suspension that remained stable for two months without forming a precipitate. Understanding how a layered host compound becomes exfoliated to form single-atom layers is important. Figure 3(b) shows X-ray diffraction (XRD) patterns for the wet colloidal aggregate that was separated from the suspension after centrifugation, and this pattern showed that the parent siloxene had been exfoliated to form individual nanosheets, a small portion of which was stacked, causing smallangle scattering. When the aggregate was dried, almost all of the siloxene nanosheets became restacked as 10-20 sheet units with basal spacings of $3.8 \mathrm{~nm}$, which is much larger than the original siloxene spacing $(0.63 \mathrm{~nm})$, leading to the species present being identified as dodecylsulfate intercalated compounds [Fig. 3(c)].
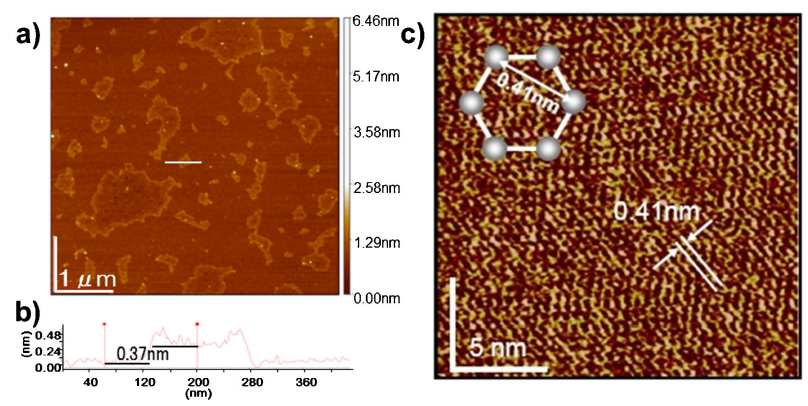

Fig. 2. (a) AFM image of the nanosheet. (b) Line profile taken along the white line in (a). (c) Atomically resolved AFM image of the nanosheet. 

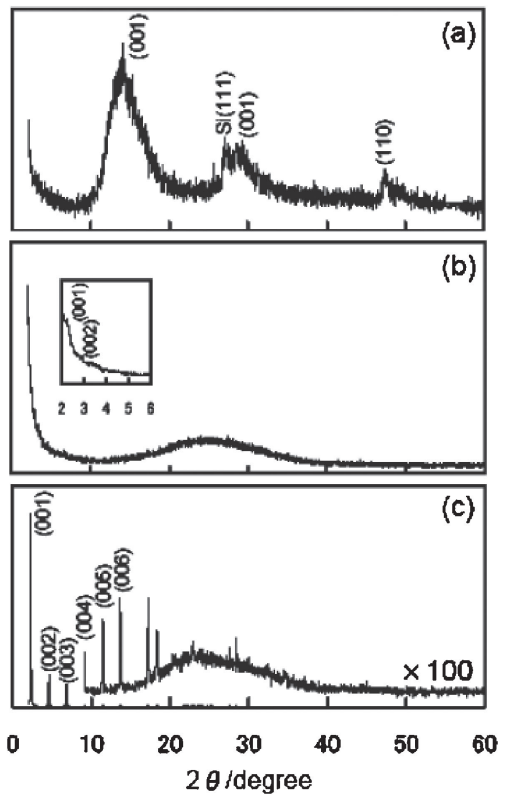

Fig. 3. X-ray diffraction patterns for (a) $\mathrm{Si}_{6} \mathrm{H}_{3}(\mathrm{OH})_{3}$, (b) the wet colloidal aggregate separated from the exfoliated $\mathrm{Si}_{6} \mathrm{H}_{3}(\mathrm{OH})_{3}$ suspension by centrifugation, and (c) the dried colloidal aggregate.

\section{Organic modifications of the nanosheets}

As stated above, layered silicon compounds were successfully exfoliated using aqueous solutions, indicating that the silicon nanosheets that were produced were covered with oxygen species. In this section, we describe the production of oxygenfree silicon nanosheets and functionalized organic modified silicon nanosheets using the methods involving organic solvents.

Layered polysilane, $\mathrm{Si}_{6} \mathrm{H}_{6}$, was used as the starting material to produce organic modified SiNSs. Using hydrosilylation ${ }^{38)}$ or the Grignard reaction, ${ }^{39)}$ the resulting materials, which were insoluble in water and ethanol, could be dispersed in some organic solvents, such as hexane, chloroform, acetone, and ether. Figure 4(a) shows the attenuated total reflection infrared spectrum of $\mathrm{Si}_{6} \mathrm{H}_{6}$ after it was hydrosilylated in 1-hexene. ${ }^{38)}$ The spectrum contains alkyl stretching and bending absorption bands between 2856 and $2954 \mathrm{~cm}^{-1}$ and between 1259 and $1459 \mathrm{~cm}^{-1}$, respectively, and a peak that was attributed to $\mathrm{Si}-\mathrm{CH}_{2}$ vibrational scissoring at 729 $\mathrm{cm}^{-1}$. The presence of characteristic vibrations after the reaction had occurred, along with a decrease in the intensity of the $\mathrm{Si}-\mathrm{H}$ band at $2110 \mathrm{~cm}^{-1}$ and the absence of peaks characteristic of terminal double bonds $\left(\mathrm{C}=\mathrm{C} ; 1600 \mathrm{~cm}^{-1}\right)$ in the products, indicate that the organic molecules were covalently attached to the silicon surface. The Si oxidation state was determined using X-ray photoelectron spectroscopy (XPS). The XPS spectrum had a Si 2p peak with a binding energy of $102.0 \mathrm{eV}$ [Fig. 4(b)], which suggests that only one type of site was present in the structure. The $\mathrm{Si} 2 \mathrm{p}$ peaks in the spectra for bulk $\mathrm{Si}(99.0 \mathrm{eV})$ and $\mathrm{SiO}_{2}(104 \mathrm{eV})$ have very different binding energies from that of the SiNS Si 2 p peak, and this is consistent with SiNS not simply being a mixture of Si and $\mathrm{SiO}_{2}$. Recently, XPS data for decyl-capped silicon nanocrystals have been reported, and the peak that was found at $99 \mathrm{eV}$ was attributed to the silicon core and at $102 \mathrm{eV}$ was attributed to the surface Si-organic groups and the oxides. ${ }^{40)}$ No peak was found at $99 \mathrm{eV}$ in the XPS spectrum of SiNS, but a peak was found at $102 \mathrm{eV}$, and this indicated that the SiNS did not have a core, but did have bonds that could be attributed to $\mathrm{Si}$-organic groups.

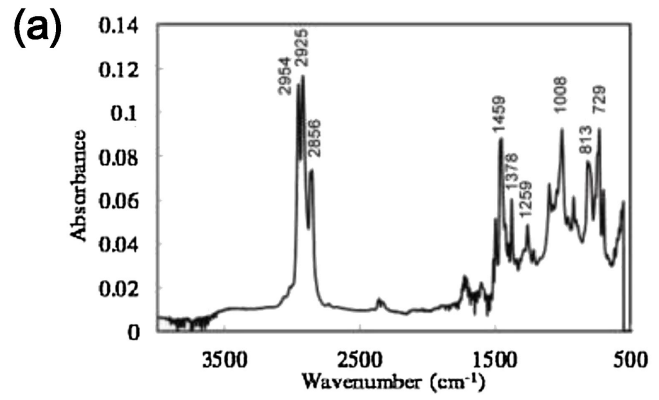

(b)

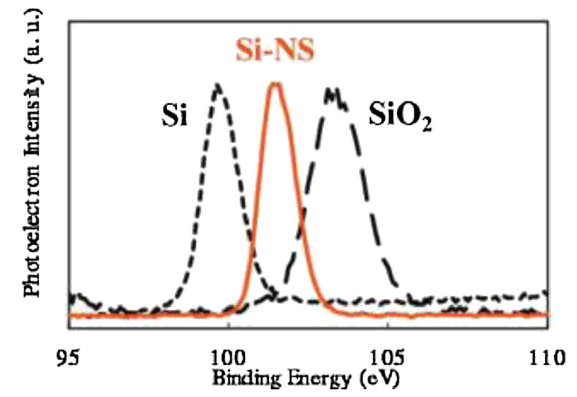

Fig. 4. (a) Infra-red spectra of hexane-terminated silicon nanosheets (SiNSs). (b) X-ray photoelectron spectroscopy $\mathrm{Si} 2 \mathrm{p}$ spectra of the hexane-terminated SiNSs (red line), a Si(111) wafer (short dashed black line), and $\mathrm{SiO}_{2}$ (long dashed black line).
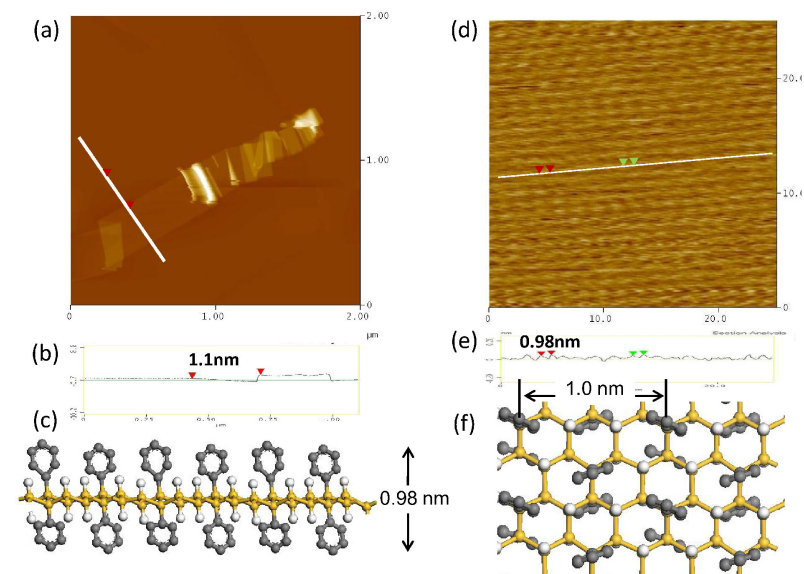

(f)

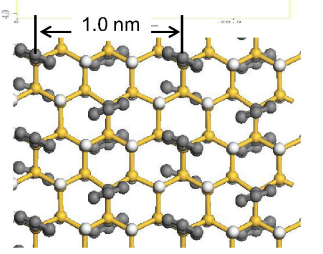

Fig. 5. (a) Atomic force microscopy (AFM) image of $\left[\mathrm{Si}_{6} \mathrm{H}_{4} \mathrm{Ph}_{2}\right]$ in contact mode. (b) Line profile along the black line in image a. (c) Side view of the model structure of $\left[\mathrm{Si}_{6} \mathrm{H}_{4} \mathrm{Ph}_{2}\right]$. (d) Atomically resolved AFM image of the surface of $\left[\mathrm{Si}_{6} \mathrm{H}_{4} \mathrm{Ph}_{2}\right]$. (e) Line profile along the black line in image d. (f) Top view of the model structure for $\left[\mathrm{Si}_{6} \mathrm{H}_{4} \mathrm{Ph}_{2}\right]$.

Introducing aromatic groups on $\mathrm{Si}_{6} \mathrm{H}_{6}$ is a plausible method for obtaining SiNSs capped with organic moieties. After numerous unsuccessful trials, phenyl-terminated SiNSs $\left(\mathrm{Si}_{6} \mathrm{H}_{4} \mathrm{Ph}_{2}\right)$ were successfully synthesized by reacting $\mathrm{Si}_{6} \mathrm{H}_{6}$ with phenyl magnesium bromide. ${ }^{39)}$ An intermediate halogenation step is usually required to allow organic groups to be introduced into bulk Si(111) using a Grignard reagent because of the low reactivities involved. ${ }^{41)}$ However, SiNSs were successfully synthesized without an intermediate halogenation step. Figures 5(a) and 5(b) are AFM images of $\mathrm{Si}_{6} \mathrm{H}_{4} \mathrm{Ph}_{2}$, which revealed that $\mathrm{Si}_{6} \mathrm{H}_{4} \mathrm{Ph}_{2}$ had a completely flat planar surface and a sheet thickness of $1.11 \mathrm{~nm}$ that was close to the thickness $(0.98 \mathrm{~nm})$ calculated from its atomic architecture [Fig. 5(c)]. The thickness and flatness of the 
$\mathrm{Si}_{6} \mathrm{H}_{4} \mathrm{Ph}_{2}$ surface indicated that the sample was composed of monolayer sheets. Interestingly, the sample had the shape of a band with a folded moiety, and it was very thin and flexible, in a manner similar to silk. Atomically resolved AFM revealed that it had periodic phenyl groups, which were seen as atom-like dots on the silicon surface [Fig. 5(d)]. The closest distance between the dots was $0.96 \pm 0.02 \mathrm{~nm}$ [Fig. 5(e)]. The periodicity of the phenyl groups in the $\mathrm{Si}_{6} \mathrm{H}_{4} \mathrm{Ph}_{2}$ structural model was estimated to be $1.0 \mathrm{~nm}$ [Fig. 5(f)], which agrees well with the closest distance between the dots in the AFM image.

Density functional theory and ab initio molecular dynamics simulations were used to investigate the properties of $\mathrm{Si}_{6} \mathrm{H}_{4} \mathrm{Ph}_{2}{ }^{42)}$,43) We also determined the optimized structural, electronic, and vibrational properties that would be useful in photocatalyst, sensor, and electrochemical device applications. The sp3 structure was retained in $\mathrm{Si}_{6} \mathrm{H}_{4} \mathrm{Ph}_{2}$ after the phenyl group functionalization step, and this structure led to it having a wide (direct) band gap, of $1.92 \mathrm{eV}$. The phenyl and $\mathrm{H}$ functional groups were covalently bonded to the nanosheet, contributing to its stability. There were little interaction between adjacent phenyl groups on the nanosheet, allowing the groups to reorient themselves, and they were preferentially oriented perpendicular to the nanosheet surface. This type of functionalized nanosheet was found to have the unique characteristic that its electronic properties could easily be varied by using different functional molecules on the sheet. That is, this type of functionalized nanosheet could be used to give a variety of properties that would be useful in electronic device and sensor applications.

\section{Regular stacking structure in organic modified SiNSs}

From the viewpoint of their applications, useful nanosheets must have high affinities for planar integrated circuits and be easily fabricated using microprocess techniques. Nanosheets made of $\mathrm{Si}$ are, therefore, suitable for use in conventional Sibased integrated circuits. ${ }^{44)}$ Stacking structures are suitable for fabricating electrochemical devices using organic modified SiNSs. We developed SiNSs modified with amino groups, and performed the amination reaction in an inert atmosphere, following a previously published method. ${ }^{45}$ ) Internal structures were detected by XRD in the agglomerated n-decylamine (C10)-SiNS state. A very strong narrow peak for C10-SiNS was found at $2 \theta=2.96^{\circ}$ [Fig. 6(a)]. This peak was related to the interlayer distances $(\mathrm{d}=2.98 \mathrm{~nm})$ of the nanosheets, and it appeared together with higher order peaks that were assigned to (001) planes. The C10-SiNS diffraction peak was associated with the stacking of the nanosheets. Therefore, we conclude that the nanosheets that were agglomerated in the concentrated state easily self-assembled to form regularly stacked structures.

The peak associated with the (001) planes in the C10-SiNSs was much sharper than the equivalent peak in $\mathrm{Si}_{6} \mathrm{H}_{6}$ [Fig. 6(c)], and the broadness of the latter peak was attributed to its small crystal size, which included approximately 10 layers. ${ }^{46)}$ The strong sharp peak for the C10-SiNSs indicated that multilayer stacking, of several tens of layers, occurred in this system. The alkyl chains in stacked $\mathrm{C} 10-\mathrm{SiNSs}$ were thought to be aligned differently from the alkyl chains in C10 crystals (Fig. 6d) because the chains were bonded with the silicon layers in the $\mathrm{C} 10-\mathrm{SiNSs}$. The $\mathrm{d}$ value $(2.98 \mathrm{~nm})$ suggested that the $\mathrm{C} 10$ residues on the corrugated silicon layers were almost perpendicular to the layers, with an extended chain conformation. The remaining $2 \mathrm{D}$ silicon crystal structure was confirmed from XRD measurements on the C10-SiNS powder in a glass capillary

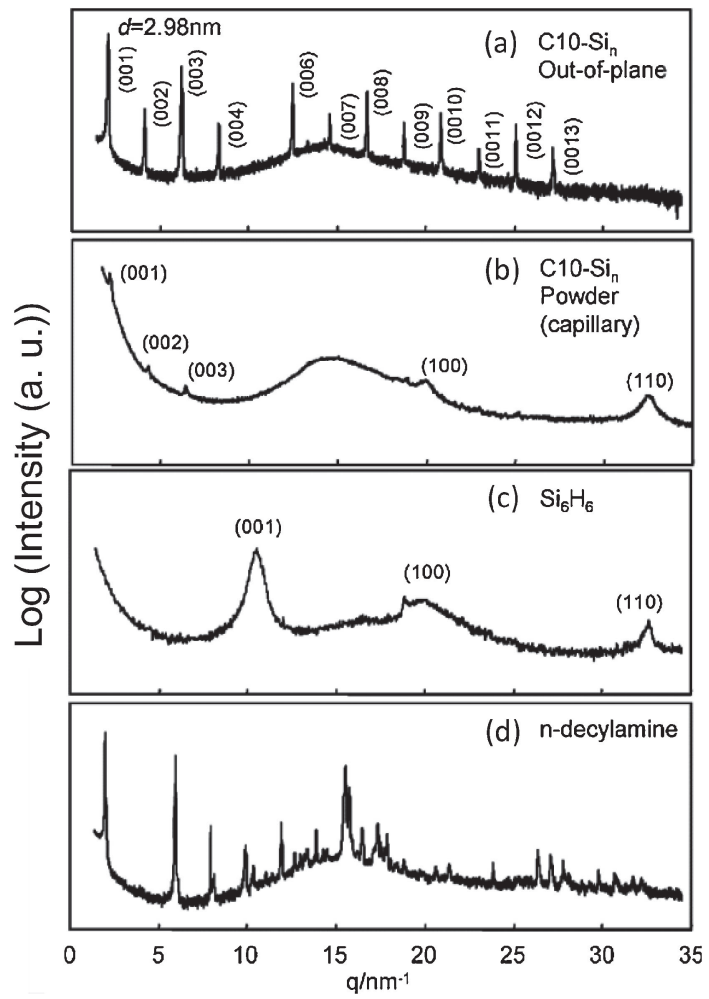

Fig. 6. X-ray diffraction patterns for [(a) and (b)] n-decylamine-Si nanosheets (C10-SiNSs), (c) $\mathrm{Si}_{6} \mathrm{H}_{6}$, and (d) $\mathrm{C} 10$ (c and d being provided for comparative purposes). (a) Out-of-plane patterns for the C10-SiNSs. (b) Pattern measured using a powdered C10-SiNS sample in a glass capillary.

[Fig. 6(b)]. Peaks corresponding to the (100) and (110) planes of the corrugated silicon sheet were observed around the q values of 20.4 and $32.8 \mathrm{~nm}^{-1}$, respectively. A few peaks corresponding to the (001) C10-SiNS planes were also observed, although higher order peaks were absent because the $\mathrm{C} 10$ residues were destroyed by the synchrotron radiation. The absence of peaks corresponding to the (001) $\mathrm{Si}_{6} \mathrm{H}_{6}$ and $\mathrm{CaSi}_{2}$ planes confirmed that the peaks caused by the (100) and (110) planes were derived from 2D silicon crystals in the C10-SiNSs.

The regular stacking structure mentioned above will have a high affinity for planar integrated circuits and can be easily fabricated using microprocess techniques. Therefore, the electron transport properties of single-layer SiNSs were investigated using AFM with a conductive cantilever, which was used to determine the number of SiNS layers and to obtain the data required to construct current-voltage (I-V) plots. ${ }^{47)}$ Figure 7 shows the I-V relationships found for the $\mathrm{C} 10-\mathrm{SiNSs} \mathrm{A}, \mathrm{B}$, and $\mathrm{C}$ immediately after the topographs were obtained. All of the I-V curves had similar nonlinear shapes, but the currents in each curve were slightly different because of the variations in the contact area between the cantilever and the different $\mathrm{C} 10-\mathrm{SiNSs}$. The three I-V curves for C10-SiNS C were almost of the same shape. The C10-SiNSs were relatively stable, and showed similar I-V characteristics over the voltage of $0-1 \mathrm{~V}$. However, the breakdown of the nanosheets occasionally occurred at a voltage $>1 \mathrm{~V}$ with a larger current being measured in the voltage sweep after the one in which the breakdown occurred, which indicated that the $\mathrm{C} 10-\mathrm{SiNS}$ had been destroyed. Although the effect of the applied electrical field on mechanical deformations in the C10SiNSs was not determined, we inferred that the strong local 
(a)

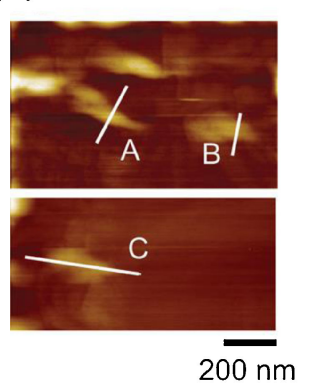

(b)

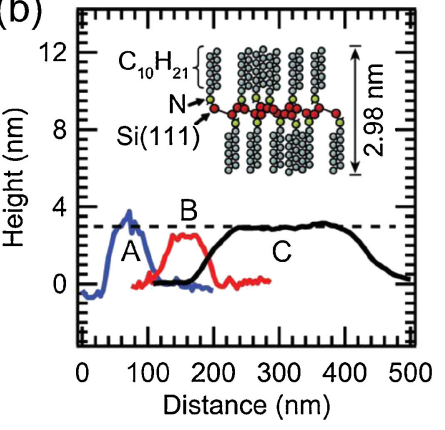

(c)

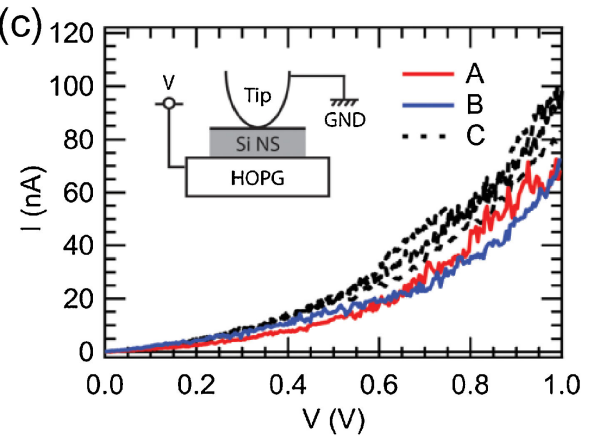

Fig. 7. (a) Atomic force microscopy images of n-decylamine-functionalized silicon nanosheets (SiNSs) dispersed on a highly ordered pyrolytic graphite substrate. (b) Line profiles for the height of the nanosheets at points A, B, and C marked on image a; inset: schematic of a single-layer SiNS. (c) I-V curves of the SiNS at points A, B, and C marked on image (a).

electrical field caused by using a sharp cantilever as an electrode could break the C10-SiNSs at high bias voltages.

The $\mathrm{Si}(111)$ atomic layer comprises a periodic structure of $\mathrm{Si}$ atoms [see the inset in Fig. 7(b)], and it was the fundamental structure in the C10-SiNSs, thus we expected the C10-SiNSs to have band structures. Organic molecules adsorbed on the $\mathrm{Si}(111)$ layers could create potential barriers against the band edges of the layers, resulting in C10-SiNSs with double-barrier quantum-well structures. However, it is unlikely that electrons could tunnel through the confinement level in the quantum well (i.e., resonant tunneling) as the confinement level was too high, because of the presence of the ultrathin $\mathrm{Si}(111)$ layers. Therefore, we concluded that the C10-SiNSs functionalized with organic molecules could possibly act as single potential barriers.

\section{Potential applications}

We expect SiNSs to be developed for use in various applications, such as in electronic and photonic devices and lithium ion battery electrodes. In this section, we review the potential applications of SiNSs. SiNSs functionalized with phenyl and larger aromatic molecules are expected to be useful in solar cells because such SiNSs have UV-vis absorption maxima at around $270 \mathrm{~nm}$. In particular, $\mathrm{Si}_{6} \mathrm{H}_{4} \mathrm{Ph}_{2}$ produced a light-induced current when it was directly irradiated using a xenon lamp. The photocurrent disappeared when the irradiation was blocked using a shutter (Fig. 8), ${ }^{39)}$ and no photocurrent was observed when a filter was used to block wavelengths of less than $420 \mathrm{~nm}$. The photocurrent was, therefore, wavelength-dependent, which indicated that the origin of the photocurrent was a bandgap transition.

Silicon nanomaterials are also expected to find applications in lithium ion battery anodes in order to increase the energy density. Silicon is known to form lithium alloys, and when $\mathrm{Li}-\mathrm{Si}$ alloys are formed electrochemically, the maximum theoretical capacity is approximately $4200 \mathrm{mAh} / \mathrm{g}$, which is much higher than the capacity achieved using conventional carbonaceous materials $(372 \mathrm{mAh} / \mathrm{g})$. However, the volume of a silicon anode changes greatly during the charge-discharge cycle, leading to cracking and pulverization of the anode and the loss of silicon particles over numerous cycles, resulting in significant capacity fade. A composite anode containing silicon nanomaterials is a plausible solution to this problem because such an anode could have minimal volume changes, avoiding the pulverization and failure of the Li alloy anode through charge-discharge cycling. SiNSs alone could also be candidate materials for use as anodes because of their sizes. The electrical capacitance and structural changes in SiNSs were examined by our research group. During the lithium insertion and de-insertion process, an electrode made of SiNSs

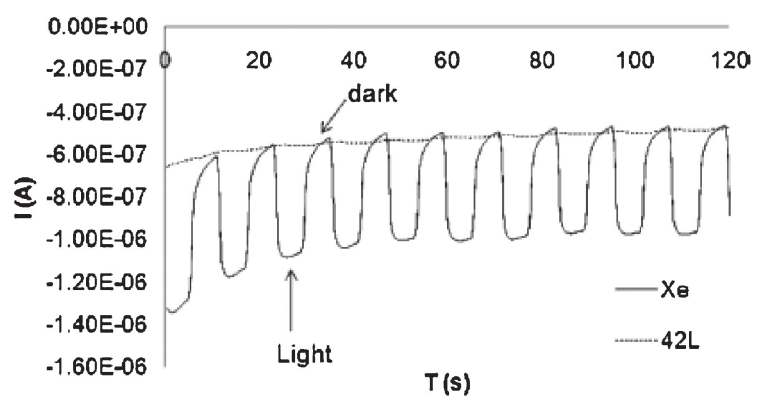

Fig. 8. Light-induced current in a $\left[\mathrm{Si}_{6} \mathrm{H}_{4} \mathrm{Ph}_{2}\right]$ film. The solid line (labeled $\mathrm{Xe}$ ) is the photocurrent in a directly irradiated sample, and the dotted line (labeled 42L) is the photocurrent in a sample that was irradiated with only wavelengths greater than $420 \mathrm{~nm}$ (obtained by passing Xe lamp emission through a filter).

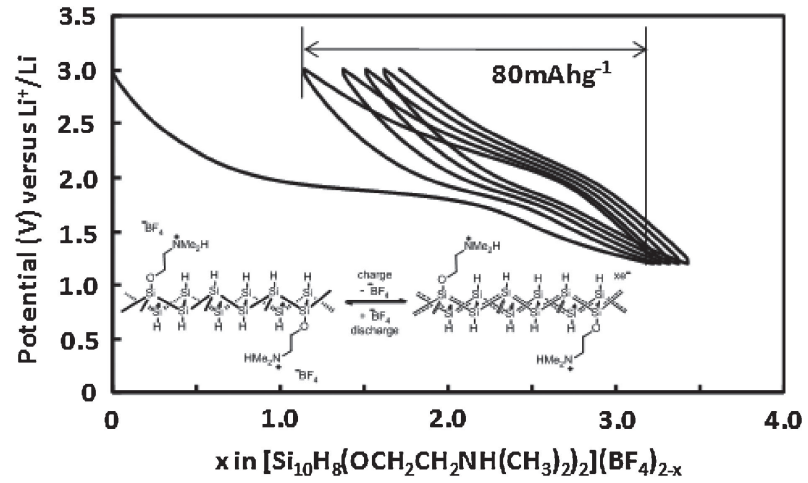

Fig. 9. Relationship between the potential produced and the composition of $\left\{\mathrm{Si}_{10} \mathrm{H}_{8}\left[\mathrm{OCH}_{2} \mathrm{CH}_{2} \mathrm{NH}\left(\mathrm{CH}_{3}\right)_{2}\right]_{2}\right\}\left(\mathrm{BF}_{4}\right)_{2-x}$, galvanostatically cycled at a rate of $\mathrm{BF}_{4}^{-} / \mathrm{h}$ against $\mathrm{Li}^{0}$. The inset shows the reaction scheme.

was found to have higher capacitance $(1620 \mathrm{mAh} / \mathrm{g})$ and smaller volume change than a Si powder electrode. ${ }^{48), 49)}$ We recently described an alternative approach for using Li cations, based on the fabrication of tetrafluoroborate $\left(\mathrm{BF}_{4}\right)$ anion rocking-chairtype secondary batteries. As the anode material, the Si-based compound $\left\{\mathrm{Si}_{10} \mathrm{H}_{8}\left[\mathrm{OCH}_{2} \mathrm{CH}_{2} \mathrm{NH}\left(\mathrm{CH}_{3}\right)_{2}\right]_{2}\right\}\left(\mathrm{BF}_{4}\right)_{2}$ was found to be capable of reacting with two $\mathrm{BF}_{4}$ anions per formula unit at a potential of $1.8 \mathrm{~V}$, giving a reversible capacity of $80 \mathrm{mAh} \cdot \mathrm{g}^{-1}$ (Fig. 9). ${ }^{50)}$ This anion battery also performed better than Li-ion batteries when they were thermally abused. Furthermore, anion batteries could operate at a temperature of $-30^{\circ} \mathrm{C}$; however, at this temperature, Li-ion batteries cannot generally operate 
because Li-ions in such batteries become solvated by coordinating with basic organic molecules.

\section{Conclusions}

We have developed a method for the soft synthesis of SiNSs by chemically modifying layered silicon compounds. The produced SiNSs maintained their characteristic 2D crystalline structure and exhibited photoluminescent characteristics that were related to their structures. Phenyl-capped SiNSs also produced photocurrents under direct UV irradiation. We expect that this new synthetic approach will be developed further using various techniques, and suggest that theoretical calculations need to be performed to predict the properties of the SiNSs produced. SiNSs have extraordinarily high specific surface areas and can be used as building blocks for fabricating devices using solution processes.

\section{References}

1) L. T. Canham, Appl. Phys. Lett., 57, 1046-1048 (1990).

2) V. Lehmann and U. Gçssele, Appl. Phys. Lett., 58, 856-858 (1991).

3) B. K. Teo and X. H. Sun, Chem. Rev., 107, 1454-1532 (2007).

4) R. A. Bley and S. M. Kauzlarich, J. Am. Chem. Soc., 118, 12461-12462 (1996).

5) R. D. Tilley, J. H. Warner, K. Yamamoto, I. Matsui and H. Fujimori, Chem. Commun., 14, 1833-1835 (2005).

6) A. M. Morales and C. M. Lieber, Science, 279, 208-211 (1998).

7) W. Molnar, A. Lugstein, P. Pongratz, N. Auner, C. Bauch and E. Bertagnolli, Nano Lett., 10, 3957-3961 (2010).

8) J. Sha, J. Niu, X. Ma, J. Xu, X. Zhang, Q. Yang and D. Yang, Adv. Mater., 14, 1219-1221 (2002).

9) M. De Crescenzi, P. Castrucci, M. Scarselli, M. Diociaiuti, P. S. Chaudhari, C. Balasubramanian, T. M. Bhave and S. V. Bhoraskar, Appl. Phys. Lett., 86, 231901 (2005).

10) T. Sasaki, M. Watanabe, H. Hashizume, H. Yamada and H. Nakazawa, J. Am. Chem. Soc., 118, 8329-8335 (1996).

11) T. Sasaki, J. Ceram. Soc. Japan, 115, 9-16 (2007).

12) R. Ma and T. Sasaki, Adv. Mater., 22, 5082-5104 (2010).

13) D. M. C. MacEwan and M. J. Wilson, in Crystal Structures of Clay Minerals and Their X-ray Identification, Ed. by G. W. Brindley and G. Brown, Mineralogical Society: London (1980).

14) P. Joensen, R. F. Frindtm and S. R. Morrison, Mater. Res. Bull., 21, 457-461 (1986).

15) L. F. Nazar and A. J. Jacobson, Chem. Commun., 7, 570-571 (1986).

16) G. Alberti, M. Casciola and U. Costantino, J. Colloid Interface Sci., 107, 256-263 (1985).

17) N. Yamamoto, T. Okuhara and T. Nakato, J. Mater. Chem., 11, 1858-1863 (2001).

18) M. M. J. Treacy, S. B. Rice, A. J. Jacobson and J. T. Lewandowski, Chem. Mater., 2, 279-286 (1990).

19) T. Sasaki and M. Watanabe, J. Am. Chem. Soc., 120, 46824689 (1998).

20) R. E. Schaak and T. E. Mallouk, Chem. Mater., 14, 1455-1471 (2002).

21) T. Hibino and W. Jones, J. Mater. Chem., 11, 1321-1323 (2001).

22) L. Li, R. Ma, Y. Ebina, N. Iyi and T. Sasaki, Chem. Mater, 17, 4386-4391 (2005).

23) R. Ma, K. Takada, K. Fukuda, N. Iyi, Y. Bando and T. Sasaki, Angew. Chem., Int. Ed., 47, 86-89 (2008).
24) R. F. Frindt, J. Appl. Phys., 37, 1928-1929 (1966).

25) R. F. Frindt, Phys. Rev. Lett., 28, 299-301 (1972).

26) D. Yang, S. J. Sandoval, W. M. R. Divigalpitiya, J. C. Irwin and R. F. Frindt, Phys. Rev. B, 43, 12053-12056 (1991).

27) K. S. Novoselov, A. K. Geim, S. V. Morozov, D. Jiang, Y. Zhang, S. V. Dubonos, I. V. Grigorieva and A. A. Firsov, Science, 306, 666-669 (2004).

28) H. Yang, J. Heo, S. Park, H. J. Song, D. H. Seo, K. E. Byun, P. Kim, I. Yoo, H. J. Chung and K. Kim, Science, 336, 11401143 (2012).

29) G. G. Guzm'an-Verri and L. C. Lew Yan Voon, Phys. Rev. B, 76, 075131 (2007).

30) A. Fleurence, R. Friedlein, T. Ozaki, H. Kawai, Y. Wang and Y. Yamada-Takamura, Phys. Rev. Lett., 108, 245501 (2012).

31) M. S. Brandt, G. Vogg and M. Stutzmann, in Silicon Chemistry, Eds: P. Jutzi, U. Schubert, Wiley-VCH, Weinheim (2003) pp. 194-213.

32) J. R. Dahn, B. M. Way, F. Fuller and J. S. Tse, Phys. Rev. B, 48, 17872-17877 (1993).

33) S. Yamanaka, H. Matsu-ura and M. Ishikawa, Mater. Res. Bull., 31, 307-316 (1996).

34) Y. Sugiyama, H. Okamoto and H. Nakano, Chem. Lett., 39, 938-939 (2010).

35) A. Weiss, G. Beil and H. Meyer, Z. Naturforsch., 34b, 25-30 (1979).

36) H. Nakano, T. Mitsuoka, M. Harada, K. Horibuchi, H. Nozaki, N. Takahashi, T. Nonaka, Y. Seno and H. Nakamura, Angew. Chem., Int. Ed., 45, 6303-6306 (2006).

37) H. Nakano, M. Ishii and H. Nakamura, Chem. Commun. (Camb.), 2945-2947 (2005).

38) H. Nakano, M. Nakano, K. Nakanishi, D. Tanaka, Y. Sugiyama, T. Ikuno, H. Okamoto and T. Ohta, J. Am. Chem. Soc., 134, 5452-5455 (2012).

39) Y. Sugiyama, H. Okamoto, T. Mitsuoka, T. Morikawa, K. Nakanishi, T. Ohta and H. Nakano, J. Am. Chem. Soc., 132, 5946-5947 (2010).

40) D. Wang, M. M. Kappes and G. A. Ozin, J. Am. Chem. Soc., 133, 11928-11931 (2011).

41) A. Bansal, X. Li, S. I. Yi, W. H. Weinberg and N. S. Lewis, J. Phys. Chem. B, 105, 10266-10277 (2001).

42) M. J. S. Spencer, T. Morishita, M. Mikami, I. K. Snook, Y. Sugiyama and H. Nakano, Phys. Chem. Chem. Phys., 13, 15418-15422 (2011)

43) M. J. S. Spencer, M. R. Bassett, T. Morishita, I. K. Snook and H. Nakano, New J. Phys., 15, 125018 (2013).

44) S. M. Sze, Semiconductor Devices, Physics and Technology, John Wiley \& Sons, Inc. (2002).

45) H. Okamoto, Y. Kumai, Y. Sugiyama, T. Mitsuoka, K. Nakanishi, T. Ohta, H. Nozaki, S. Yamaguchi, S. Shirai and H. Nakano, J. Am. Chem. Soc., 132, 2710-2718 (2010).

46) J. R. Dahn, B. M. Way, E. Fuller and J. S. Tse, Phys. Rev. B, 48, 17872-17877 (1993).

47) T. Ikuno, H. Okamoto, Y. Sugiyama, H. Nakano, F. Yamada and I. Kamiya, Appl. Phys. Lett., 99, 023107 (2011).

48) Y. Kumai, H. Kadoura, E. Sudo, M. Iwaki, H. Okamoto, Y. Sugiyama and H. Nakano, J. Mater. Chem., 21, 11941-11946 (2011).

49) Y. Kumai, S. Shirai, E. Sudo, J. Seki, H. Okamoto, Y. Sugiyama and H. Nakano, J. Power Sources, 196, 1503-1507 (2011).

50) H. Nakano, Y. Sugiyama, T. Morishita, M. J. S. Spencer, I. K. Snook, Y. Kumai and H. Okamoto, J. Mater. Chem. A, 2, 7588-7592 (2014). 


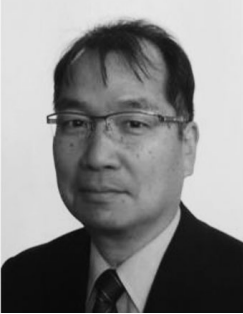

Hideyuki Nakano reserved his Master and Doctor degrees of Engineering from Hiroshima University in 1988 and 1993, respectively. He joined NEC Co. as a Researcher in 1988. He moved to TOYOTYA Central Laboratory as a Researcher in 1997, and was promoted to Senior Researcher in 2005. His research field is inorganic materials chemistry: current research interests are silicon layered structured compounds, silicon nanosheets, and soft chemical synthesis. 